\title{
An Analysis on the Change of Gender Language over Time
}

\author{
Wang Shu'e ${ }^{\mathrm{a}}$, Chen Yiting ${ }^{\mathrm{b}}$ \\ Xiamen University Tan Kah Kee College, Xiamen, Fujian, P. R. China \\ a.cloud9818@xujc.com \\ b.2514939993@qq.com
}

Keywords: Gender language, gender difference, Big Brother.

\begin{abstract}
Many linguists are convinced that gender differences in language are inevitable. However, with the change of social status of men and women, the stereotype of typical male language and female language is disputable in certain sense and to some extent. In the framework of stylistic analysis and conversational analysis, this thesis analyzes the change of gender differences in language over time. Examples are collected from Big Brother, a social experiment reality show. It is found that, in the process of language communication, the difference in gender language is gradually fading.
\end{abstract}

\section{Introduction}

Language differences between men and women exist in all languages all the time. Danish linguist Otto Jespersen(1922) published his book Language: Its Nature, Development and Origin, which marked the beginning of the study of gender language in modern linguistics. In this book, Jespersen discussed the characteristics of women's language and pointed out gender differences in vocabulary and syntax. With the deepening of social linguistics and the feminist movement, the systematic study of gender language really started. Robin Lakoff's Language and Women's Place (1975) raised people's awareness of how deeply related language might be to female and male identities.

The gender differences in language are mainly manifested in vocabulary, syntax and choice of topics. For instance, it is believed that women use discourse modifiers as mitigating devices to adjust and modify their mood, for example "perhaps", "maybe", "probably", "I think", while men use "most", "many", "I am sure". In addition, many studies have shown that men are more casual than women in using swear words. (Meng, 2011)

On the syntax level, men usually present their opinions directly. Declarative sentences and imperative sentences are often used by men, while women are inclined to use exclamation and ellipsis to express their feelings. (Zhuang, 2008) For example:

(1) The crisis in the Middle East is terrible.

(2) The crisis in the Middle East is terrible, isn't it?

Tag question is associated with tentativeness and indicates the lack of confidence in the speaker. According to Lakoff, the first sentence that is more assertive is likely from men, while women often choose the second sentence that contains a tag question. In order to make their expressions as euphemistic and polite as possible, women usually like to add some language fuzziness like "I think", "I guess”, "I suppose”, “you know”, etc. to express their opinions.

As for choices of topics, Ren Haitang (2007: 125) pointed out that men's topics are more abstract like sports, politics, economy and religion, and they like to promote their own achievements; while women talk more about housework, children, appearances and dress, mutual friendship and so on.

Many scholars are convinced that the difference in language between men and women is caused by their different social roles and social division of labor. The Difference Theory, put forward by Daniel Maltz and Ruth Borker, claims that physiological and cultural differences between men and women eventually lead to language differences. According to the doctrine of Dominance Theory, the unequal status of men and women in power eventually led to the imbalance between men and women in language communication. (Wang, 2009) 
However, with the development of the society, women are becoming an equal counterpart of men in almost every aspect. With the differences in social status and social division of labor between men and women are fading, the gender language is undergoing a great change. It is the focus of this paper to explore the change of gender language in modern society by analysing data from Big Brother, a reality show.

\section{Analysis on Gender Language in Big Brother}

\subsection{The Reality Show Big Brother}

Big Brother is a social experiment reality show created by John de Mol Jr., broadcast in the Netherlands and subsequently syndicated internationally.The United States version of the series officially premiered on July 5, 2000 and, as of September 26, 2018, 706 episodes of Big Brother have aired.

In the show, 16 contestants including 8 males and 8 females called "housemates" (or "House Guests") live together in a specially-constructed house that is isolated from the outside world. Housemates are voted out (usually on a weekly basis) until only one remains and wins the cash prize. During their stay in the house, contestants are continuously monitored by live television cameras as well as personal audio microphones.

The reasons for choosing the 19th season of Big Brother as a corpus for the present research are as follows:

(1)This reality show is built on the back-to-basics environment. There are not too many artificial settings and they are closer to life.

(2)The proportion of males and females is equal. Throughout the show they will not only communicate with each other, but also express their thoughts, emotions, and frustrations.

(3)The contestants in the program come from a variety of cultural backgrounds. They come from all walks of life and have different personalities.

\subsection{Gender Difference on Lexical Level}

\subsubsection{Words with Intensive Emotions}

Previous studies have shown that the high frequency of using intensive expressions such as "so", "very", "quite", "really", "extremely", "absolutely", "definitely", etc. in dialogues is one of the characteristics of women's language, which reflects the lack of self-confidence and the low social status of women. In traditional society, women did use more intensive expression to make their voice and thoughts heard in man-dominated world. However, such phenomenon is changing. In Big Brother, both men and women frequently use words with intensive emotions to attract others' attention.

The use of intensive expressions is no longer an exclusive feature of women. Following sentences are examples of men's uses of expressions with intensive emotions in Big Brother:

(1) Mark: I'm definitely full of energy. (EP01, 06:09)

(2) Ramses: I can absolutely win Big Brother, it is my sports. (EP01, 07:36) It is absolutely crazy, I like it! (EP01, 10:46)

(3) Matt: I'm definitely sweating, because I absolutely do not want to go home at day one. (EP01, 53:26)

(4) Cameron: Only been there 12 hours really breaks my heart. I'm really disappointed myself. I should have stay longer in this competition. (EP01, 84:28)

(5) Josh: I know it's extremely bad $\cdots$ and it's extremely unacceptable $\cdots$ I was completely wrong. I don't know what got into me. I feel that I'm completely a bastard. And I completely respect that $\cdots$ (EP02, 33:37)

(6) Cody: I ain't worried about it. I just really respect the chick, you know? (EP04, 07:04) I seriously look at you as, like, Wonder Woman. (EP04, 08:58) Personally, I have. (EP04, 09:05) I genuinely do not like that girl. (EP08, 08:07) 
(7) Jason: Cody's propose for me is absolutely unrealistic. But I literally stand in my back of the cliff. (EP04, 35:13) There is definitely water in my ear. (EP09, 16:16)

(8) Kevin: I seriously do want to compete against you. (EP04, 40:54)

It is a surprise that men even use more intensive expressions than women. One possible explanation is that all female contestants have their own career, and also have their own places in society. They do not need to depend on men and do not need to use intensive expressions to prove their status. On the other hand, men are equally eager, if not more, to prove their positions in the competition and show their strength, so they tend to use intensive expressions in daily conversation. 2.2.2 Swear Words and Interjections

Linguists generally believe that women's language is more emotional than those of men. Yang Yonglin (2004:148) observes that women often attach strong emotional colors in verbal communication. When expressing surprises, women seem to particularly enjoy using interjections such as "Oh dear”, “Goodness”, "My God”, "Dear me”, etc. However, it is more common for men to use interjections derived from swear words such as "shit”, "fuck”, “damn”, and other indecent words with insults, words that women try their best to avoid. Compared with men, women's expression seems more elegant and implicit.

With the passage of time, society is constantly changing, and the gender differences mentioned above are continually fading. Stronger expletives are not only reserved for men as the weaker ones not for women. Following sentences are examples of men's using weak expletives.

(1) Ramses: Oh, my god, it's gorgeous! Oh my god, you're so big! (EP01, 10:32) Oh my god, you can't sleep on it! (EP03, 12:44)

(2) Jason: Oh, dear, I'm here! I made it! (EP01, 22:15) Good gracious! I won’t digest this kind of garbage. (EP03, 11:17)

(3) Josh: Goodness! It’s Paul! He is back! (EP01, 38:48)

(4) Matt: Oh gosh! I can't tolerant it any more. (EP02, 08:37)

(5) Cameron: Being voted again? $\underline{\mathrm{Oh}}$, come on, don’t bully me ! (EP02, 14:13)

(6) Kevin: Oh, well, let it go. (EP02, 24:51)

(7) Mark: My God, how can you believe her? (EP02, 36:19)

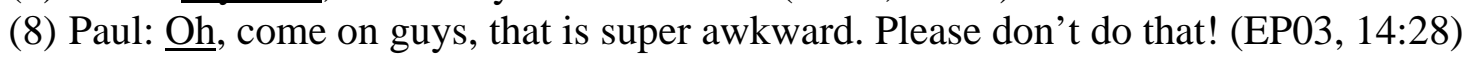

In this reality show, all the swear words are reviewed and silenced when introduced into China, so it is impossible to record the swear words spoken by the players. However it is possible to analyse the usage of swear word by counting the frequency of silenced times in Big Brother. The swear words spoken by males to females are 52 times to 48 times. The difference on using swear words between men and women is not quite significant. Although the show was reviewed and edited before broadcasting, it is not difficult to see from the collected data that, nowadays, the proportion of men and women using curses is not much tilted. As women become stronger and stronger, they no longer worry about others' opinions and they feel they are free to use swear words to express their anger. This doesn't make women vulgar or obscene. It is just a way of venting their feelings.

\subsection{Gender Difference on Syntactical Level}

\subsubsection{Tag Question}

Tag question is a grammatical structure in which an interrogative fragment is appended to a declarative statement or an imperative. According to Lakoff, tag question is related to tentativeness, and indicates the lack of confidence in the speaker. Although both men and women use tag questions in some occasions, women use much more tag questions than men, which signals their politeness and hesitancy to themselves. However it is found that there is no significant difference between females and males in terms of use of tag questions in Big Brother.

(1) Ramses: But he is really bad, isn't he? (EP01, 41:32)

(2) Josh: That eight for Jillian, that's shock, right? (EP02, 06:13)

(3) Jason: Well, the good news is I'm a way bigger target than you are, isn't it? (EP03, 04:49)

(4) Paul: He’s like this stone cold, isn’t he? (EP04,33:34) 
(5) Cody: Wow, she must be a beast, right? (EP14, 11:47)

\begin{tabular}{|l|l|l|}
\hline & Tag question (EP01-10) & Ratio \\
\hline Male players & 26 & $47.27 \%$ \\
\hline Female players & 29 & $52.73 \%$ \\
\hline
\end{tabular}

It can be concluded that, as women become more independent and obtain more social power and status, men also need to seek advice from women or show their respect by using tag questions.

\subsubsection{Hedges}

Like tag questions, hedges, such as "I think/I believe/ we think...”, “you know…”, "I' m afraid...””,

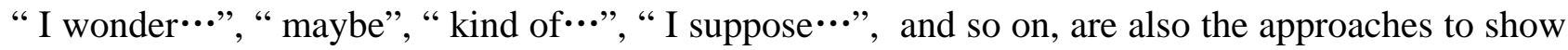
politeness. The use of hedges can soften the tone, and shows that the speaker lacks self-confidence or he/she is not sure about the information given. Previous studies have suggested that women use hedges more often than men as a display of weakness and subordination to males.

However, in order to stay in the game for a longer time, both male and female housemates in this reality show prefer to use the hedges as a "lubricant" when expressing their ideas with the others so as to maintain a good interpersonal relationship. The following are some typical hedges used by men housemates:

Ramses: I think he's going to go with the boys. (EP01, 41:43) But you know, I'm thinking like this $\cdots($ EP07, 13:42)

Cody: But as far as I'm concerned, I want it to be me, you and Mark. (EP02, 31:29) I knew we were. (EP02, 32:50)

Josh: I know that I'm the last person you want to talk to $\cdots$ but, when you get a chance, like, if I can have a conversation with you, if that's okay? (EP02, 33:19)

Paul: I think it's gonna be Jason. (EP04, 33:06) Nobody doesn't trust you, you know, we're just trying to avoid all possible failure. (EP07, 17:52) I'm afraid you have to go home this week. (EP08, 24:31)

\subsection{Gender Difference in Choice of Topics}

Usually the topic of conversation depends on factors such as personal interests, social background and the motivation of conversation. Previous studies have shown that men talk more about sports, politics, economy, religion, and other more abstract issues, while women talk more about housework, children, fashion, and dress. This is mainly due to the fact that in the past, the roles of the two genders were quite different. Women were mostly unemployed and they could only use family life (such as housework, children, etc.) as their topic.

Through the observation of the conversational scenes in Big Brother, it is found that there is no significant difference in choice of topics between genders. Housemates talk more about the reality show itself rather than other topics because of the nature of this program. However, there are some occasions that men use family as a topic to win others' favor. For example:

Josh: You know, I mean... I've been some tough, but I keep thinking my dad is alone and my mum is alone, and everything else doesn't matter.

Mark: Miss your parents. I can understand...You can see your dad in October. Your mum is home, she is healthy. So Josh, you gonna see them. But I can't.

This conversation is initiated by Josh after he felt frustrated because of the game. In order to comfort Josh, Mark tells him the story of his parents' passing away when he was a child. After this conversation, the two men get closer.

Another conversation takes place between two women, Cody and Christmas. Christmas is a team member of NASCAR (National Association for Stock Car Auto Racing), a popular car race in the United States which women rarely pay attention to. In the show, the two girls talk about the race, which is typical topic for men. 


\section{Summary}

As a cultural carrier, language changes reflect social changes. This thesis takes the gender variable as the research object, and tries to discuss gender and language from the perspective of social constructivist gender theory. Examples collected from the reality show Big Brother demonstrate that language expressions that were regarded as "feminine exclusive" in the past also appear in men's language nowadays. High frequency of using intensive expressions and modal verbs are no longer typical features of women's language, and likewise, women use swear words and strong expletives as frequently as or even more frequently than men. The use of tag question and hedges are common in conversations no matter what the speaker's gender is. Men and women do not have too many restrictions in choice of topics.

\section{References}

[1] H.T. Ren, An Analysis of Conversations of Men and Women in "Friends", Journal of Northwest University (Philosophy and Social Sciences Edition), vol.5, pp.122-126, 2007.

[2] L. Q. Wang, The Tendency of International Gender Language Researches in the $21^{\text {st }}$ Century, Journal of Xi'an International Studies University, vol.17, pp.48-52, 2007.

[3] O. Jespersen, Language: Its Nature, Development and Origin, London: Allen \& Unwin, 1922.

[4] R. Lakoff, Language and Women's Place, New York: Harper \& Row, 1975.

[5] Y. Meng, On the Trend of Convergence and Similarity in Gender Language, Changchun: Jilin University, 2011.

[6] Y. L. Yang, A Study of Sociolinguistic Issues: Function, Titles and Gender, Shanghai: Shanghai Foreign Language Education Press, 2004.

[7] Y. J. Zhuang, Gender Differences in English of the 19th Century, Qingdao: China University of Petroleum, 2008. 